\title{
LA PROTESTA DE LOS JEFES EN 1948: UNA TRADICIÓN ORAL NACIONALISTA EN GUINEA ECUATORIAL
}

\author{
Gonzalo Álvarez Chillida ${ }^{57}$ \\ Universidad Complutense de Mdrid
}

\begin{abstract}
Resumen: En 1948 varios jefes de la zona continental de la Guinea espańola entregaron a una comisión de tres ministros que visitaba la colonia dos escritos de protesta por la situación de los nativos. El de Mikomeseng, localidad fronteriza con el agitado Camerún, mereció el castigo de sus dos principales promotores. A diferencia de similares protestas anteriores, la de 1948 se transmitió oralmente y desde los ańos sesenta los nacionalistas la convirtieron en el origen de su movimiento.
\end{abstract}

Palabras clave: Guinea española, Protesta anticolonial, Nacionalismo africano, Oralidad.

AвsтRACT: In 1948 several chiefs of the mainland area of Spanish Guinea gave to a commission of three ministers, who were visiting the colony, two writings protesting about the natives' situation. The two main promoters of the protest in Mikomeseng, a little town located near the troubled Cameroon, were punished. Unlike some previous similar protests, this was not silenced and was orally transmitted. Since the sixties the nationalists converted the protest of 1948 in the origin of its movement.

57 (gachilida@ucm.es) Universidad Complutense de Madrid / Facultad de CC. Políticas y Sociología / Campus de Somosaguas / 28223 Madrid — Esta investigación se ha realizado en el marco del proyecto del Ministerio de Economía e Investigación «Lo que sabemos, ignoramos, inventamos y deformamos acerca del pasado y el presente de Guinea Ecuatorial. Revisión crítica multidisciplinar y nuevas vías de investigación» (HAR2012-34599). Agradezco sus sugerencias y opiniones a Rafael Cruz, Sasha Pack, Juan Aranzadi, Benita Sampedro y a los demás participantes del II Seminario Internacional sobre Guinea Ecuatorial, celebrado en Madrid en julio de 2015. 
KeYword: Spanish Guinea, Anticolonial Protest, African Nationalism, Oral Transmission.

\section{Introducción}

En enero de 1948 la Guinea española se desarrollaba económicamente, a partir de las plantaciones de cacao de Fernando Poo, las explotaciones madereras del continente, ambas con mano de obra nigeriana, y las pequeñas fincas de cacao y café de los nativos. Estos productos abastecían a una metrópoli cuya autarquía económica, impuesta por el régimen franquista, impedía importarlos de otros países. El Gobierno colonial, además, tenía superávit presupuestario que ayudaba a financiar la Administración de las otras posesiones africanas.

Para impulsar este desarrollo, en enero de ese año visitó la colonia una comisión de tres ministros, presidida por el del Aire, Eduardo González Galarza, junto al de Agricultura, Carlos Rein, y de Industria y Comercio, Antonio Suances, acompañados por el director general de Marruecos y Colonias, José Díaz de Villegas. Como informó $A B C$, el objetivo de la visita era incrementar el desarrollo económico mediante «los proyectos en vías de ejecución [que] influirán notablemente en la economía general de España». ${ }^{58}$ A su regreso, según la versión oficial, los ministros informaron al Gobierno del éxito de su viaje, y afirmaron que los nativos los habían recibido «con entusiasmo verdaderamente desbordante», aclamando «al generalísimo Franco, que goza entre la población indígena de una devoción y popularidad verdaderamente extraordinaria». ${ }^{59}$

\section{La protesta de Mikomeseng}

El día 18 de enero de 1948 la comitiva ministerial, acompañada por el gobernador Juan María Bonelli, visitó Mikomeseng, en la zona central de la frontera con Camerún. La agencia Cifra informó de que fueron recibidos por «una multitud inmensa», de unos "diez mil indígenas». Presidieron un "desfile de tribus y poblados», encabezados por sus jefes: "cada tribu pasaba al ritmo de sus bailes y danzas primitivas y prorrumpía en vivas entusiastas a España y al Caudillo». Los visitantes regresaron a Bata «altamente satisfechos». Una vez allí, sigue la

58 Editorial, $A B C, 30-1-1948$, p. 7.

$59 A B C, 7-2-1948$, p. 7. 
información, antes de los actos oficiales de la noche, estuvieron «estudiando en las dependencias oficiales diversos problemas». ${ }^{60}$ En esta curiosa reunión previa a la cena oficial, que no se dio en las otras jornadas, al menos según la crónica de Cifra, se habló quizás de un suceso habido en Mikomeseng algo diferente a los entusiasmos populares vividos. De hecho, si el 21 de enero Bonelli felicitaba por radiograma al subgobernador por la «magnífica impresión» que se llevaban del continente los cuatro visitantes, al día siguiente le enviaba otro radiograma, pero cifrado, y el 27 le urgía contestación. ¿Qué había pasado? ${ }^{31}$

Según informó después el administrador territorial local, Basilio Sáez Hernández, en la tarde del 17 de enero se reunieron en el local del Tribunal de Raza de Mikomeseng casi todos los jefes de dicha demarcación y los de la vecina de Ebebiyín, ambas de población fang, a fin de cambiar impresiones sobre las peticiones que podrían hacer a los ministros al día siguiente. De las versiones que le dieron varios de los participantes, parece que debatieron qué aspectos incluir en la petición, y que el funcionario auxiliar administrativo Marcelo Asistencia Ndongo, destinado en la localidad, redactó el escrito que se entregaría a los ministros, «basándose en la propuesta redactada por los Jefes».

El texto que redactó dice así:

RESUMEN DE LAS CONSULTAS DE LOS JEFES DE ADMINISTRACIÓN REGIONAL DEL ESTE E INDIGENAS EN GENERAL quieren hacer a los grandes de España y a nuestro querido Excmo. Sr. Gobernador general, en su visita a Mikomeseng, y toda y la colonia

Piden cesen las burlas que los blancos nos hacen en general, en lugar de colonizar. Que todos los ramos de la Colonia nos hacen burla.

Piden la ampliación de estudios de los chicos capacitados hasta obtener una carrera y estudios en España. Que no está bien quitar a un chico de la Escuela a los 12 años, cuando es una edad propia para el estudio.

60 La Vanguardia, 20-1-1948, p. 1, y 22-1-1948, p. 1.

61 Archivo General de la Administración, Alcalá de Henares (AGA), África, C(aja) 81/7779.

ÉNDOXA: Series Filosóficas, n. 37, 2016, pp. 121-147. UNED, Madrid 
Piden las consideraciones de un español negro estudiado y no despreciarles como hacen hasta el momento: Que nos consideran como peores a los que hayan ido a la Escuela. También deben guardar las consideraciones debidas a los Jefes de tribus.

Piden la justicia para todos: blancos y negros. Que aqui se hace solo por el color.

Piden instalaciones de industrias por parte del patronato de Indigenas para beneficio de los naturales del pais, donde podrian aprender oficios. Que el dinero del patronato solo lo trabajan a los blancos. Además deben poner al frente de algunos puestos a indigenas capacitados.

Piden mejora de precios de sus productos y abaratamiento de géneros. Nosotros debemos poner precios a nuestros productos o bien marcar un precio equitativo para nuestro bien.

Para nuestro bien y tranquilidad para nuestra España colonizadora, solicitamos del Gobierno español, que cada cinco años conceda autorización para entrar en Consejo de Ministros a exponer nuestras quejas. Dicha comisión de españoles morenos estará compuesta de tres indigenas, nombrados por los nativos del país. El dinero que podrán realizar el viaje a España y regreso, podrá correr por cuenta del Patronato de Indigenas, si al cabo de cinco años no viniese ninguna comisión, será señal de que ya está haciendo mal.

Copia literal en papel con el membrete de la Administración Territorial de Mikomeseng

El punto $7^{\mathrm{o}}$, de tono un tanto conminativo y poco respetuoso, especialmente en la advertencia final, fue el que más censurable pareció al administrador Sáez, pues en su informe fue el único que transcribió literalmente, no mencionando los demás. En él se demandaba el derecho a elevar quejas periódica y directamente al Gobierno español, a través de una comisión electiva de nativos. ${ }^{62}$

62 El documento de la protesta, el informe del administrador de Mikomeseng y las informaciones que siguen proceden, salvo que se indique otra referencia, de AGA, África, C 81/7534, exp. Carmelo Enguema. La carrera de Asistencia como funcionario, en AGA, África, C 81/9033, exp. 4 Marcelo Asistencia Ndongo: «Antecedentes». 
Sáez informaba de que durante la mañana del día 18 el instructor de la Guardia Colonial (suboficial espańol) del puesto de Mikomeseng tuvo conocimiento del escrito de protesta, posiblemente a través de uno de los jefes, y dio parte al capitán administrador de Ebebiyín, Pérez Vázquez, por estar él en Nkué esperando la llegada de los ministros y autoridades. ${ }^{63}$ El capitán interrogó a varios de los jefes y les dijo que no debían presentar el escrito, pero le contestaron que, aunque ellos estaban de acuerdo en no hacerlo, quien lo tenía era Carmelo Nguema, primer jefe de la tribu esambé, quien manifestó que lo iba a entregar «aunque le mataran, pues él no tenía miedo y estaba dispuesto a morir por el bien de los morenos». Y así lo hizo. Para Sáez los demás jefes habían formulado propuestas razonables con buena intención. Proponía así que sólo se castigase al jefe Carmelo Nguema y al administrativo Marcelo Asistencia, quien había actuado "con perversas y mezquinas intenciones». Del relato parece deducirse que todos o casi todos los presentes dieron su aprobación a la protesta pero, cuando al día siguiente fueron interrogados por el capitán Pérez Vázquez, se echaron atrás. Y tuvieron éxito, pues la represión por el suceso se limitó a los dos personajes citados.

\section{La represión}

Carmelo Nguema fue encarcelado y luego deportado a la pequeña isla de Annobón, a donde «deberá marchar completamente solo», según ordenó el gobernador. Llegó el 24 de marzo. $\mathrm{Al}$ año siguiente solicitó dos veces al gobernador que le levantara el confinamiento. Decía que desobedeció al administrador por una «debilidad» suya, «incitado» por los otros jefes, y añadía: «Que habiendo confesado mi delito confieso mi sincero arrepentimiento", jurando no volver a delinquir y adherirse a España y su Caudillo. El administrador Sáez propuso denegarle la solicitud, pero el subgobernador accidental Bosch de la Barrera, ante los informes de buena conducta y arrepentimiento del jefe de la Guardia Colonial en Annobón, propuso dejarle regresar cuando se constituyera la nueva Administración de Añisok, a dos kilómetros de Mokok, el poblado de Nguema, donde podía ser fácilmente vigilado. Esto es lo que decidió el sucesor de

63 En la versión de Fortunato Nzang Okenve poco antes de su muerte, reproducida en EYAMA (s.a.), los jefes confiaron la carta a Moisés Mba Nsono, «muy amigo de los blancos», para que la entregara a los ministros, pero no se atrevió y se la dio a su amigo el capitán Pérez Vázquez. 
Bonelli, el gobernador Faustino Ruiz, quien, finalmente, ordenó el 8 de mayo de 1951 que se le liberara del destierro. Habían pasado 3 años y 3 meses desde su detención.

Marcelo Asistencia fue también detenido, pero en febrero de ese 1948 se fugó de los calabozos de Mikomeseng, huyendo al vecino Camerún. Según informó el administrador Sáez al año siguiente, su actitud antes del incidente había sido buena, pero en Camerún «estuvo en íntimas relaciones con los familiares del diputado comunista Duala Manga» (realmente democristiano). Según su hoja de "Antecedentes», había sido allí detenido por deudas. Lo cierto es que pidió retornar. El subgobernador Chicharro Lamamie de Clairac aconsejó al gobernador que se le permitiera, ya que "ha pasado cierto tiempo y parece estar arrepentido». Regresó el 6 de noviembre. Había dejado deudas en la colonia, pero el administrador territorial no consintió que se saldaran con su finca y su corral, que quedaron bajo la administración de un tío y del jefe de tribu de su clan onvang, en beneficio de su mujer e hijos. El 8 de diciembre fue embarcado para su destierro en Annobón, y en mayo de 1949 se acordó su separación definitiva de su cuerpo de funcionarios y se fijó su destierro en (sólo) seis meses. Regresó, y al poco el administrador de Mikomeseng informó de que en «su reciente estancia en esta Demarcación ha hecho manifestaciones de tipo político, tales como que S. E. el Gobernador le había indultado y repuesto en el escalafón por su propio valer por lo cual los demás indígenas debían seguir sus instrucciones». «Su presencia en esta Demarcación provocó un movimiento de simpatía entre los indígenas, llegándose inclusive a intentarse cuestaciones para compensarle de los daños sufridos por la causa de los indígenas». Es claro que semejante informe debió asustar al gobernador Faustino, pues sabemos que volvió a huir a Camerún, donde, acusado de robar una pieza de motor, fue encarcelado y luego (según su costumbre) se fugó. Retornado a Guinea debió ser nuevamente detenido, pues no mucho más tarde le vemos huyendo del buque de la Marina que le llevaba deportado de nuevo a Annobón. Huyó nuevamente a Camerún, donde estuvo varios años y fue dos veces arrestado. Posteriormente declaró que entró en la colonia el 12 de agosto de 1955, pensando en presentarse a las autoridades, pero que antes visitó a varios amigos y familiares, y envió una carta al vicario Leoncio Fernández pidiéndole que intercediese ante las autoridades para que le perdonaran. Fue detenido finalmente en Mikomeseng, y en el interrogatorio dio amplia información sobre el movimiento revolucionario camerunés del UPC (Union des peuples 
camerounaises), filocomunista. ${ }^{64}$ Enviado nuevamente a Annobón, en mayo de 1956 se le permitió regresar a su pueblo bajo vigilancia, aunque al mes siguiente fue encarcelado un mes "por hacerse pasar por policía y cobrar exacciones en los poblados cercanos». Al año siguiente solicitó infructuosamente su reingreso en la Administración colonial. En 1960 él y el exjefe Carmelo Nguema comenzaron a aparecer entre los activistas nacionalistas, siendo estrechísimamente vigilados y en ocasiones detenidos por participar «en actividades antiespañolas». ${ }^{65}$

En el Archivo General de la Administración (AGA) hay un curioso documento del Vicariato Apostólico, pero con el membrete arrancado y sin fecha ni firma, con informaciones sobre los dos «Deportados en Annobón». De Carmelo Nguema decía que, pese a ser católico y casado canónicamente, es "polígamo empedernido». «Para nosotros, los misioneros», era de los jefes más hostiles a la misión. El texto mostraba el apoyo sin fisuras de los claretianos a la represión de toda disidencia, y denunciaba además a otros dos indígenas para que se les investigase. La animadversión de los misioneros al exjefe Nguema debía estar relacionada con un escrito suyo al administrador territorial de Mikomeseng en 1944, que le informaba de que "algunos catequistas» estaban tomando nota de los nombres de los jefes y de sus mujeres, todo en medio de rumores de que a los jefes les iban a quitar todas sus mujeres menos una. ${ }^{66}$

\section{La protesta de Río Benito}

Durante la visita de los ministros y del director general al continente hubo otro escrito de protesta colectiva, una instancia firmada el 17 de enero de 1948 por cinco jefes de la demarcación de Río Benito, el mismo día en que todos los

64 AGA, África, C 81/9169, exp. 64, Marcelo Asistencia: Administrador territorial Bejarano a subgobernador, 16-9-1955; administrador regional Olaechea a subgobernador, 17-101955.

65 AGA, África, C 81/9033, exp 4 Marcelo Asistencia Ndongo: «Antecedentes» y documentos sobre sus actividades antiespañolas en 1960-1962; C 81/7534, exp. Carmelo Enguema: Administrador territorial de Mikomeseng a subgobernador, 22-8-1949; C 81/9169, exp. 64, Marcelo Asistencia: Capitán Pérez Vázquez a subgobernador, 4-1-1951; C 81/9033, exp. Carmelo Nguema Ndongo: Referencia del Subgobierno de la Guinea Continental, s.f.

66 AGA, África, C 81/8214, exp. 2; C 81/7534, exp. Carmelo Enguema: Delegado de Asuntos Indígenas a gobernador, 19-7-1944. 
de la zona costera se reunieron con los ministros en Bata. Eran estos los kombes Luis Masoko, Dionisio Djombe, Pablo Evita y Alfonso Otavenga y el bujeba (bisió) Antonio Bama, que saludaban a los ilustres visitantes como «Los indígenas de la Demarcación de Río Benito». Se trataba de una lista de siete quejas, que esperaban sabrían resolver, por la "confianza que siempre hemos tenido de la Patria España». Aunque ańadían: «Sabemos que una vez publicadas estas quejas a su retorno seremos castigados como siempre, por eso como últimas quejas se las manifestamos». El texto denunciaba que la cárcel era "horrorosa», peor que en los demás países y colonias (argumento que reiteraban), pues se ingresaba con una tanda de « 25 palos hasta 100 y 200», y se seguían recibiendo cotidianamente, se forzaba a un trabajo «indecible» y se alimentaba con sólo cinco yucas al día. Se denunciaba el empleo sistemático de la prestación personal de trabajo sin remuneración en todos los servicios coloniales, salvo el Forestal, pese a existir presupuesto para la contratación de braceros. Y ello desde la salida del anterior gobernador, Mariano Alonso, quien, atendiendo una queja anterior, había suspendido la prestación. Se quejaba también el escrito de que el Patronato de Indígenas no daba crédito a todos los indígenas que lo necesitaban para sus «finquitas» y que la Cámara Agrícola no les permitía contratar braceros para cultivarlas, con lo que se arruinaban. La Administración Territorial, por otra parte, les obligaba a venderle huevos, gallinas y cabras a un precio enormemente inferior al que pagaban los particulares. Los precios de los productos europeos, por el contrario, estaban carísimos. Denunciaban también que «toda joven» entre los 15 y los 24 años "es enteramente para el europeo», y muchas acababan abandonando a sus maridos, sin tener tampoco la ansiada descendencia porque «los europeos resultan estériles». «El pueblo indígena disminuye considerablemente por la prostitución» y por el resto de situaciones descritas: «si prosiguen en estas condiciones supondría esto el total exterminio de sus moradores [del país], de donde se deduce que, no tenemos ningún derecho a la vida». ${ }^{67}$

Los jefes firmantes no se equivocaron del todo, porque fueron detenidos junto a un empleado de la compañía Izaguirre, Angel Diaga, que había mecanografiado el texto. De las declaraciones tomadas se concluyó que la protesta se decidió en una reunión de varios jefes, que «era unánime y recogía el sentir de todos los Jefes de la Demarcación", que la redactó Pablo Evita y que luego él y sus cuatro compañeros fueron a pedirle a Diaga que la mecanografiara. Llevaron después la instancia al "Jefe de la Tribu Benga» Santiago Uganda, «quien les

67 AGA, África, C 81/7534, exp. Carmelo Enguema: Instancia a Ecmos. Sres Ministros , s.f. 
ordenó lo firmaran, siendo después entregado el referido escrito a los Excmos. Sres. Ministros por aquél». El subgobernador le decía a Bonelli que el escrito estaba lleno de falsedades y «de mala fe», y refutaba algunas de las denuncias: sólo cincuenta hombres trabajaban en la carretera mediante prestación remunerada, el Patronato había concedido en la demarcación 18.200 ptas. en créditos para vivienda y 11.500 ptas. para las fincas, de las que 2.590 fueron para Otavenga y Evita, no precisaban braceros para trabajarlas pudiendo ayudarse de la familia y sólo se les compraba "comida para los guardias, Hospital y presos». ${ }^{68}$

El 26 de enero Uganda envió un radiograma al gobernador Bonelli preguntando por el motivo de los encarcelamientos, quien le contestó, sin responderle, censurándole haberse dirigido a él directamente, sin pasar por el subgobernador. Tres días después éste informaba a Bonelli de que Diaga había entregado otra carta del propio Uganda en la que copiaba el pacto de 1843 entre Lerena y su antecesor, Bonkoro, "para concederles carta de nacionalidad", exigiéndole que cumpliera lo prometido en un plazo de seis meses. Pero, posteriormente, Uganda declaró ante el subgobernador que el radiograma lo había escrito un hijo suyo residente en Gabón, que estaba de visita en su casa. ${ }^{69}$

Aunque las denuncias del escrito de Río Benito son mucho más radicales que las de Mikomeseng, la represión fue mucho más liviana, debiendo limitarse a un corto periodo de detención y a la bronca que debió echarles el subgobernador, según anunciaba en su escrito a Bonelli, para hacerles ver la falsedad de sus denuncias. En documentos de años posteriores vemos a varios de estos jefes en sus cargos, incluyendo a Pablo Evita. Según Pelissier, Uganda sufrió confinamiento en su isla de Corisco, junto al estuario del Muni, algo que no hemos visto confirmado en el Archivo, y que, de ocurrir, pudo deberse a sus actividades posteriores. $^{70}$

68 AGA, África, C 81/7534, exp. Carmelo Enguema: Subgobernador acctal. a gobernador, 13-2-1948.

69 AGA, África, C 81/7534, exp. Carmelo Enguema: Radiograma de Uganda, 26-1-48; Gobernador a subgobernador, 27-1-1948 y a Uganda, 27-1-1948; subgobernador acctal. a gobernador, 29-1 y 13-2-1948. E. ARROJAS, "Los ministros del Aire, Industria y Comercio, Agricultura y el director general de Marruecos y Colonias visitan la Guinea Española”, Africa, no 74, 2-1948, pp. 3-6, dice transcribir la carta de Uganda, llena de manifestaciones de espanolidad y vítores a Franco.

70 AGA, África, C 81/9058, exp. Pablo Evita Monanga; C 81/9065, exp. Alfonso Otavenga. PELISSIER (1966), p. 77. 


\section{Las actividades del jefe benga Santiago Uganda}

En la protesta de los jefes de Río Benito vemos el papel destacado de Santiago Uganda, que se autoproclamaba «rey» de los bengas, Bonkoro III, sucesor de Bonkoro I. Él había entregado el escrito de los jefes a los ministros españoles y también un escrito propio que parece que exigía el cumplimiento de las promesas expresadas en 1843 en el (supuesto) tratado de unión a la soberanía española suscrito por el capitán Juan José Lerena y el «rey» Bonkoro. Realmente, cuando la expedición Lerena llegó aquel año a Corisco, sus habitantes le recibieron con los brazos abiertos pues esperaban que España restaurara las factorías esclavistas españolas que los británicos habían destruido tres ańos antes. Pero Lerena no firmó ningún documento con el «rey» de la isla, Oregeck, sino que se limitó a redactar un acta de toma de posesión. Boncoro era uno de los jefes locales que apoyó con más entusiasmo a los españoles, y por ello Lerena le nombró «jefe de la punta del sur de la isla». Dos años después Guillemard de Aragón, al mando de una nueva expedición oficial, sí quiso reforzar la soberanía española logrando que Oregeck y otros jefes firmaran un documento de anexión a España, gracias a los buenos oficios de Boncoro (NERÍN, 2015: 60 y 67-70).

Aunque desconocemos el contenido cierto de su carta a los ministros, lo cierto es que Uganda adoptó poco después varias iniciativas de claro cariz anticolonial e incluso nacionalista, aunque personales y al margen de todo grupo organizado. La primera, cuando el 28 de diciembre del mismo 1948 logró enviar una carta a Franco, presentándose como «Santiago Uganda de Uganda Ngola "Bonkoro III" privado de su cátedra por los representantes del Gobierno de España que ejercen sus poderes en esta Colonia». En ella elevaba las quejas de «su gente» a «su Superior Autoridad». La primera: «La injusticia, maltrates y trates de esclavitud», junto a las "Grocerias e ingratitudes» que sufrían los nativos, y que sólo se daban en la colonia española. «Esta pequeña Colonia está llorando y llorara con voz más alta para que todo el mundo se oiga de sus lloros, ya que su querida madre España no se interesa ni se escucha de los lloros de sus propios hijos naturales del país». Seguía denunciando que dos españoles habían asesinado a un indígena con total impunidad, y un alemán a otro. Y concluía:

«el "Pacto de Anexión" que en 1843 se hicieron entre el Capitán de Navío Don Juan José de Lerena, en nombre de la reina de España y de la Nación de la misma y el Rey Bonkoro I (Bedipo) dueño de esta Colonia, de la tribu Benga en nombre propio y de sus tribus, no era con carácter del régimen establecidas hoy día, ni con caracter de la venta de la Colonia, ni tampoco con caracter de disminuir a los propios, hijos naturales del país 
sus derechos en ella, ni tampoco era para establecer el trato de esclavitudes y matar a los cuerpos humanos hijos del país sin motivos para ello, asi como, no era tampoco, para convertir el terreno propio legítimo del Estado. (...) el caracter del Pacto era de Anexión pero hoy día estaconvertido guerra en contra del hijo del país.

¿Cuando gozaremos de la libertad como gozan nuestros paisanos de colores de nuestros paises vecinos? cuando veremos la luz del sol de la justicia.» ${ }^{71}$

A diferencia de protestas anteriores, que por radicales que fueran a veces, no cuestionaban la dominación española, sólo sus excesos, Uganda estaba afirmado en este escrito que las injusticias del orden colonial suponían una ruptura del (supuesto) pacto de anexión de 1843, pacto que, además, no afectaba sólo a Corisco, ni siquiera a todos los bengas, sino a toda la colonia y «sus tribus», de la que Bonkoro era «dueño». Era, pues, un texto protonacionalista, aunque no llegara a pedir la independencia sino las libertades que gozaban ya los nativos de las colonias vecinas.

El Pardo envió la carta a la Dirección General de Marruecos y Colonias para que le informaran sobre su contenido, y Díaz de Villegas se dirigió al gobernador Faustino Ruiz pidiéndole que le informara "de manera objetiva para hacerlo, a mi vez, en el mismo sentido». La autoridad colonial sólo investigó el caso del indígena muerto por el alemán, que dijo haberle disparado estando de caza por confundirle con un faisán que se movía tras las ramas. El caso estaba tramitándose en el Juzgado. ${ }^{72}$

Poco después de su carta a Franco, Uganda, firmando como «El Jefe Supremo»y «el Bonkoro $3^{\circ}$ », comenzó a actuar con una autoafirmada autoridad que le equiparaba a la de los españoles, cuando el 20 de abril de 1949 escribió al subgobernador de Bata notificándole lo siguiente:

«en virtud de las facultades que me están conferidas por el pueblo indígena de estos territorios, según el acuerdo de la Junta celebrada el día $1^{\circ}$ de febrero de 1948 en Bata (...) vengo en nombrar como Delegado del mencionado Jefatura general en la repetida isla de Fernando Poo a Don Federico Ebuka Eyamba. (...) Lo que me honro comunicar

71 AGA, África, C 81/7534, exp. Santiago Uganda.

72 AGA, África, C 81/7534, exp. Santiago Uganda: Director general de Marruecos y Colonias a gobernador, 26-2 y 2-3-1949 y contestación, 12-5-1949. 
a V.I con el ruego de ponerlo en conocimiento del Gobierno General de estos territorios para que sea publicada en el periódico local de la Capital».

Me parece claro que la reunión de jefes a la que alude es la celebrada el día 17 de enero de 1948, cuando la recepción de los ministros en Bata. Uganda interpretaba que la confianza que depositaron entonces en él los jefes de Río Benito suponía un reconocimiento explícito de su suprema autoridad entre el conjunto de los nativos. ${ }^{73}$

El 2 de diciembre de 1949 Uganda dio un paso más, anticipándose a la que sería principal estrategia de los partidos nacionalistas guineoecuatorianos a partir de 1959: la apelación a las Naciones Unidas. Escribió entonces al secretario general de la organización denunciando las violaciones de los Derechos Humanos en la colonia. La Secretaría General contestó diciendo que se habían tomado buena nota de su denuncia pero que, según las normas de la institución, no tenía competencia para hacer más. Este escrito fue interceptado por las autoridades. ${ }^{74}$

\section{La práctica de protestar por escrito}

Las dos protestas colectivas de jefes «tribales» de 1948 no eran, en modo alguno, las primeras. En otras coyunturas anteriores también se había dado el caso de que unos grupos de jefes (una pequeña minoría entre todos ellos) habían elevado por escrito sus quejas antes las autoridades españolas. Tras destituir al gobernador Núñez de Prado, el Gobierno Provisional envió a la colonia en el verano de 1931 a Ricardo Ferrer como comisario de la República, para que informara de la situación. En los meses de agosto y septiembre recibió varias decenas de escritos e instancias, individuales y colectivos, con peticiones y quejas. ${ }^{75}$ Varios de los escritos iban firmados por jefes individuales. Uno venía firmado por ocho jefes de Río Benito y otro por diez de Bata. Otro, de «Los bubis», tenía 19 firmas, y otro más era firmado por 14 ones de Punta Embonda, cuatro de los cuales precisaron y ampliaron luego sus denuncias ante un juez instructor. Todas estas iniciativas

\footnotetext{
73 AGA, África, C 81/7534, exp. Santiago Uganda.

74 AGA, África, C 81/7534, exp. Santiago Uganda: secretario general de la ONU a Uganda, 20-1-1950.

75 AGA, África, C 81/6426, exp. 6.
} 
aprovechaban que el comisario de la República había venido, precisamente, a recabar informaciones y recibir quejas.

Ya en plena dictadura franquista, en junio de 1942, con motivo de la primera visita al continente del nuevo gobernador Mariano Alonso, éste recibió dos escritos de protesta, firmados por 7 jefes de la demarcación de Bata, casi todos ndowés, y por 23 de la de Río Benito (casi todos fang o bisiós), conteniendo sendos listados de agravios. ${ }^{76}$

Muchos son los temas comunes a todas estas protestas, incluyendo las de 1948, y vamos a enumerarlos:

La injusticia «imponente» que sufrían los nativos por parte de los blancos, los malos tratos, la discriminación, humillaciones, trato esclavista, etc., aparecían en todos los escritos colectivos citados, con la excepción, curiosamente, del de Mikomeseng de 1948. Los más contundentes son el de Bata de 1931, que habla de víctimas mortales por las frecuentes palizas, y el de Río Benito de 1948.

El trato inhumano dado a los jefes, con humillaciones públicas e incluso malos tratos, se denunciaba en dos de las protestas individuales de 1931 (jefes Bakale Enchina y Nkogo Belogo) y los dos escritos de 1942. En el de Mikomeseng se aludía en tono muy comedido.

Los abusos de la prestación personal de trabajo, sin salario ni ración, con malos tratos, utilizada para todo, aparecía en dos quejas individuales de 1931 (Obama Ntema y jefe de Ureka), en las dos de 1942 y en la de Río Benito de 1948.

El maltrato en la cárcel, con palos constantes, trabajos atroces y abusos sexuales de las presas, se denunciaba en los dos escritos de Río Benito del periodo franquista.

La recluta forzada de braceros del continente para la isla, masiva a finales de los años veinte, al interrumpirse la llegada de los liberianos, aparecía sólo en dos escritos de 1931 (Julio Ngoma y jefes de Bata). Pero la persecución de la vagancia como medio para forzar la contratación aparecía en la declaración de

76 AGA, África, C 81/8182: Instancia de siete Jefes Indígenas, 12-6-1942, e Instancia de los Jefes de Río Benito, 9-6-1942. 
los cuatro ones ante el instructor en agosto de 1931, y en el escrito de los jefes de Bata de 1942. La brutalidad del trato a los braceros, con pésimas condiciones laborales y de alojamiento, malos tratos y falta de asistencia sanitaria, causante de miles de muertos, denunciado por los bubis y los ones de 1931, desaparecía en las protestas del periodo franquista, sin duda porque para entonces la inmensa mayoría de los braceros eran foráneos.

Los textos de Río Benito de 1942 y 1948 denunciaban que los administradores territoriales obligaban a los campesinos a suministrarles comida baratísima, cuando no se la llevaban gratis los guardias coloniales.

La defensa de las economías familiares ocupaban varias de la protestas: en 1931 se denunciaba la usurpación de las tierras de los nativos por el Estado en beneficio de los blancos (jefes Manuel Ngion, Salvador Mas, Ekan Nfele y jefes de Bata). Esta denuncia directa desaparecía en 1942 y 1948, pero se mantenía la petición de defensa de la pequeña finca indígena, pidiendo mejores precios para el café o el cacao, el acceso al crédito y a la contratación de braceros (jefes de Bata y de Río Benito de 1931 y los cuatro textos del periodo franquista). En el de Bata de 1942 y el de Río Benito de 1948 se protestaba también por el alto precio de los productos europeos importados, queja debida a la elevada inflación en España desde la Guerra Civil y a la escasez de los años cuarenta. También se protestaba la prohibición de sacar madera del bosque (jefes de Bata de 1931 y escritos de 1942), que se explicaba porque, desde los ańos veinte, con la concesión a las compañías madereras de enormes masas forestales de la zona continental costera, muchos poblados se vieron desposeídos de los recursos que les daba el bosque en que vivían (NERÍN, 2015: 243-245).

Si en 1931 los jefes de Río Benito y los bubis solicitaban que, salvo en los casos penales graves, los conflictos, sobre todo familiares, se dirimieran exclusivamente ante los nativos, según su costumbre, los jefes de Bata de 1942 concretaban su protesta en la persecución de la poligamia y el divorcio, que el Gobierno colonial franquista había comenzado a combatir con mayor energía, instigado por los misioneros claretianos. En este sentido, los elogios a la Misión católica, presente en muchos escritos de 1931 (jefes de Bata, bubis, ones y jefe de Ureka), desparecen bajo el franquismo. Y no sólo: la protesta de Bata de 1942 denunciaba directamente los altos derechos que cobraban los misioneros por bautizar, y su lucha contra la poligamia y el divorcio. 
Los jefes de Bata en 1942 y los de Río Benito en 1948 denunciaban la explotación sexual de las jóvenes nativas por los blancos.

Bastantes de los escritos demandaban una más efectiva acción colonial y civilizadora: más escuelas, e incluso estudios medios y superiores, más asistencia sanitaria, que en 1931 se denunciaba que, además de insuficiente, se cobraba a precios inasequibles (en 1931 los jefes de Bata, el jefe Manuel Ndongo, los bubis y los ones, y los jefes de Bata en 1942 y de Mikomeseng en 1948).

Finalmente, muchos de los escritos pedían participación y derechos políticos para los nativos. Muy especialmente en 1931, ante las expectativas que abría el nuevo régimen republicano. Si los jefes de Río Benito pedían entonces «derechos políticos, (...) a los que efectivamente lo merezcan y sepan» (refiriéndose a los de la costa), emancipación para todos los alfabetizados y mayor participación nativa en los Consejos de Vecinos (equivalente de los Ayuntamientos), los bubis solicitaban transformar las jefaturas en Ayuntamientos elegidos cada cuatro años, cuyos alcaldes asumieran la justicia indígena y las competencias del orden público, desapareciendo de los pueblos la Guardia Colonial (que pedían que se compusiera de bubis); estos alcaldes elegirían un "Consulado bubi» que los representase en Santa Isabel y un Tribunal Indígena, con mayoría de nativos, que sustituyera la labor protectora del Patronato de Indígenas y la Curaduría. Los jefes de Bata pedían en 1942 la elección de juntas indígenas que preservaran sus costumbres, advirtiendo que sólo las autoridades injustas podían temerlas. Advertencia ésta similar a la que vimos en el escrito de Mikomeseng. A diferencia de las demandas democratizadoras de 1931, que pedían instituciones nativas con verdadero poder, las del periodo franquista se limitaban a reclamar la elección de juntas o comités que pudieran elevar quejas para defender sus intereses.

\section{Los jefes «tradicionales»y la protesta anticolonial}

Antes de la ocupación española, la organización social de los fang del interior del continente era lo que los antropólogos funcionalistas denominan una sociedad segmentaria, en la que cada poblado era independiente de los demás, con los que mantenía alianzas que se activaban en caso de conflicto, y que buscaba las alianzas matrimoniales exogámicas con los clanes vecinos para mantenerse en paz y seguridad. La comunidad de varones, en la que destacaban los cabezas 
de las familias poligínicas ampliadas, era la que regía la vida de los poblados, al margen de que pudiera haber hombres sobresalientes por su prestigio que ejercían un cierto liderazgo en la comunidad basado en su capacidad persuasiva, aunque sin poder coactivo de ningún tipo sobre sus vecinos (BODLEY, 1996: 16-18 y 76-77; HARRIS, 1971: 306-322; LEWELLEN, 1983: 37-53). El comercio directo o indirecto con los europeos, desde la segunda mitad del siglo XIX, fue enriqueciendo a algunos de ellos (nkukumas), especialmente en el número de mujeres y, por tanto de hijas, lo que suponía mayor producción en las huertas (roturadas por los hombres pero cultivadas por las mujeres) y mayores ingresos en bienes diversos, incluyendo una "moneda" nativa llamada bikuele, por el matrimonio de sus hijas a través del precio o la «riqueza de la novia» (bridewealth). Cuando los exploradores europeos contactaban con estos poblados buscaban a algún hombre sobresaliente al que llamaban «jefe», «rey», «reyezuelo», etc., a fin de «firmar» con él un «tratado» de adhesión a la nación del explorador, sometiéndolo a su soberanía, normalmente a cambio de regalos y de una bandera que debería izar en el poblado. ${ }^{77}$

El caso de los bubis de Fernando Poo es algo diferente: pese a vivir en un medio parecido de bosque tropical, cuando los europeos llegaron a la isla en el siglo XIX parece que constituían (según Tessman y Aymemí) sociedades estratificadas, o cuando menos con jerarquías de rango, y aunque los poblados (pequeñas rancherías muy dispersas) gozaban de una amplia autonomía unos de otros, parece que en ellos eran mayores los poderes de los llamados botukus o mochukus, que los españoles llamaron también reyes o jefes (ARANZADI, 2016). El caso de los pueblos llamados por los españoles "playeros» (ndowés, bisiós y otros), se asemejaba más, probablemente, a la acefalia de los fang, aunque el temprano comercio con los europeos (en la primera mitad del siglo XIX la trata de esclavos), había desarrollado más la riqueza y poder de sus hombres notables, nuevamente considerados reyes por los españoles (NERÍN, 2015: 49).

Lo que no tiene duda es que los españoles crearon las figuras de jefe de poblado y, más aún, de tribu, reforzando su poder de control sobre los habitantes de su jurisdicción, aunque subordinándolos al poder del Estado colonial, muy especialmente a los jefes de los puestos de la Guardia Colonial, llamados desde 1935 administradores territoriales. A cambio de otorgarles distinciones, privilegios, y

77 ARANZADI (2009), p. 82, n. 23: «La sociedad fang precolonial era una sociedad acéfala, ácrata, sin Estado ni jefaturas. Los primeros etnógrafos de los fang [Tessman y Largeau] son taxativos al respecto". 
a veces incluso un sueldo, además de la bandera y el retrato del rey. De ello era plenamente consciente el capitán de la Guardia Colonial Francisco Rancaño, que escribía en 1943 que «Los fang carecían de jefes» antes de su colonización. Los ricos nkukumas carecían de autoridad, salvo temporal, normalmente en tiempo de guerra, aunque tuvieran «relativo prestigio». «Autoridades permanentes no han existido hasta que fueron creadas por nosotros», afirmaba aludiendo a los jefes de poblado y tribu (RANCAÑO,1943: 1, 5-6 y 17-18).

En Fernando Poo, el «Botuko Malabbo», hijo y sucesor del mítico «rey» Moka, que parece que a finales del siglo XIX tenía cierto poder sobre los «jefes» o «reyes» de la zona sudoriental de la isla, recibió el 29 de julio de 1906, de manos del comisario regio Diego Saavedra su nombramiento de "Jefe de los poblados bubis de toda la isla de Fernando Poo» en atención a «la lealtad que demuestra», con potestad sobre todos los bubis y capacidad para resolver sus conflictos, pero subordinado al Gobierno colonial, con obligación de dar cumplimiento a sus órdenes e informar «de todo suceso grave ocurrido». ${ }^{78}$

$\mathrm{Al}$ año siguiente el gobernador Ramos Izquierdo reguló las responsabilidades de los jefes: la resolución de los conflictos ("palabras») dentro de las instrucciones del Gobierno, el mantenimiento de los poblados, la acogida de los europeos en tránsito, la persecución de las fugas y la difusión del amor a España. El decreto decía que eran designados "por acuerdo unánime y elección de los notables de la tribu», pero el gobernador tenía la última decisión. Este gobernador creó la figura de jefe de tribu (normalmente clan de un grupo étnico), en la senda del anterior nombramiento de Malabo. Esta política llevó al nombramiento, hacia 1911, de Santiago Uganda como jefe de todos los bengas, los de Corisco y los de Cabo San Juan, cuando sólo lo era de algunos poblados de la isla. ${ }^{79}$

78 AGA, África, C 81/8182, exp. 6. TESSMAN (2008), p. 238: «Aunque el gobierno español está intentando conseguir el fortalecimiento del acatamiento al jefe por parte de la tribu y de la tribu al jefe supremo en Moka, no lo ha conseguido. En realidad ha sucedido todo lo contrario, ya que ningún bubi se preocupa para nada de que el jefe sea un señor con poder de vida y muerte ni de que el jefe supremo de Moka ostente el mando sobre todos los bubis».

79 Decreto del Gobierno General (DGG), 28-5-1907. Todas las disposiciones se encuentran ordenadas cronológicamente en MIRANDA JUNCO (1945). NERÍN (2015), pp. 193196. Autores ndowés (grupo etno-lingüístico al que pertenecen los bengas) hablan de que Uganda fue proclamado rey de los bengas en 1906, al parecer con poco fundamento documental. 
El control de los administradores sobre los jefes fue aumentando con el tiempo, y se extremó bajo el franquismo, cuando los claretianos presionaron para destituir a los (muchos) que seguían practicando la poligamia, que hemos visto que era la forma tradicional de manifestar su poder y estatus social. En 1926 una disposición del gobernador primorriverista Núñez de Prado modificó el modo de su nombramiento, que en adelante sería atribución exclusiva de los gobernadores en propiedad, a propuesta de los subgobernadores, quienes deberían elevar informes con las cualidades y méritos de los candidatos propuestos. Ya no se hablaba de elección. Buscaba jefes dispuestos a proporcionar hombres para la construcción acelerada de caminos y pistas en el continente recién ocupado, y para la recluta forzada de braceros para las plantaciones de Fernando Poo, y no dudó en destituir y condenar a trabajos forzados a quienes se negaron. ${ }^{80} \mathrm{En}$ tiempos del gobernador Mariano Alonso, un documento de 30 de agosto de 1943 incluía una lista de 117 jefes del distrito de Bata, con un breve informe de cada uno, incluyendo su conducta y cualidades, otra de 94 jefes dados de baja, por «no tener nombramiento» o por fallecimiento, aunque alguno por anterior destitución, y una última de diez de los que se proponía su destitución, la mitad por «mala conducta» o desobediencia. Aunque en algunos casos se hablaba de que los jefes habían sido o debían ser elegidos en sus poblados, su subordinación al poder colonial era evidente. Un año después el gobernador Bonelli ordenaba que, para asegurar la evolución de la costumbre indígena hacia «la civilización cristiana», en adelante todos los nuevos jefes debían ser "de los indígenas de moral más firme», por lo que debían ser monógamos prácticos, y si dejaban de serlo serían destituidos (art. 1). A cambio se les concedía el usufructo de una parcela de seis o cuatro hectáreas, según el rango, adscrita a la Jefatura, no al jefe, que sería explotada mediante prestación personal gratuita de los vecinos (arts. 2 a 4) ${ }^{81}$ Carmelo Nguema, el represaliado por la protesta de Mikomeseng, había sido elegido con anterioridad, y aunque estaba bautizado, era un polígamo de facto, nada amigo de los claretianos, como vimos.

En todo caso, si los jefes eran una invención de la colonia, con un poder de control sobre los nativos reforzado por la autoridad española, aunque completamente subordinado a ésta, su modo de comportamiento era bastante más ambiguo. Situados entre dos aguas, por decir así, cuidaban de su propio poder e intereses, lo que les forzaba a ser sumisos con las autoridades, pero buscaban también la mayor aquiescencia posible entre sus convecinos subordinados, lo

80 DGG, 10-7-1926. NERÍN (2015), p. 249.

81 AGA, África, C 81/9035, Exp. Acacio Mañé. Ordenanza del GG, 29-8-1944. 
que les conducía a intentar velar por sus intereses ante la autoridad y a tratar de implementar las órdenes que recibían del modo más benigno posible para aquéllos. De ahí que en ciertas ocasiones algunos elevaran su voz para protestar contra las injusticias que sufrían los nativos, lo que, sin duda, elevaba su prestigio entre ellos. Debían pensar también que podrían obtener alguna mejora de las autoridades a las que se dirigían. El caso más diáfano es el de 1931, donde el cambio de régimen, la destitución del gobernador y la llegada del comisario de la República permitía abrigar esperanzas de mejora. En 1942 algunos esperaron que el nuevo gobernador Alonso pudiera rectificar al menos alguna de las injusticias denunciadas. En enero de 1948 Bonelli llevaba cuatro años como gobernador, pero la visita de sus superiores, los ministros enviados directamente por Franco (que así es como se presentaron ante los jefes), animaron a algunos a informarles de las injusticias que debían ignorar y que quizás desaprobaran. No en balde casi todos los escritos de protesta solían apelar al discurso legitimador de la colonización para argumentar sobre las injusticias que denunciaban: la labor civilizadora de España, la identidad española de los nativos injustamente agraviados, portadores por tanto de derechos, etc. Se atacaban aspectos esenciales de la realidad colonial, no para anularla, sino para mejorarla y hacerla acorde a su propio discurso. Y se pedía también más colonia: más escuela, mejor sanidad, mayor protección a sus fincas de productos comerciales.

\section{La tradición oral de la protesta de 1948}

A diferencia de las anteriores, la protesta de 1948 dejó una honda huella en buena parte de la población guineana, y circularon relatos orales, de lo que tenemos algunos testimonios en los ańos sesenta, que comenzaron a ponerse por escrito a partir de los ochenta. Y dentro de la protesta de aquel año, la de los jefes fang de Mikomeseng dejó mayor huella que la de los ndowés y bisiós de Río Benito, pese a que el texto de éstos era bastante más contundente. Hay dos notables diferencias entre las fechas de 1942 y 1948 que pueden explicar este diferente impacto: la represión, especialmente de la protesta de Mikomeseng, y la situación de África, y muy especialmente de las colonias africanas, como el mismo Camerún francés, inmediato a la citada población guineana, a partir de 1944 y 1945 . Cuando a finales de los años cincuenta surgió un movimiento nacionalista organizado, éste interpretó la protesta de 1948 como su propio preludio u origen, incluso la primera petición formal de independencia. Y así se transmitió oralmente el suceso. Algo lejano a la realidad del mismo, pese a la 
posterior actitud del jefe Uganda y el más tardío activismo nacionalista de los represaliados Carmelo Nguema y Marcelo Asistencia. El que los dos promotores del escrito de Mikomeseng fueran castigados, a diferencia de los del mucho más duro de Río Benito, puede explicarse porque fueron las autoridades españolas las primeras que interpretaron aquélla como una amenaza al orden colonial, en clave nacionalista, debido a lo que estaba pasando en el inmediato Camerún y a la interrelación entre los habitantes de ambos lados de la artificial frontera, en muchos casos parientes, lo que no ocurría en la ciudad de la costa.

En efecto, a partir de la Conferencia de Brazzaville de enero de 1944, en las vecinas Gabón y Camerún se extendieron derechos de una nueva ciudadanía de la Unión Francesa, que incluían libertades políticas (de partidos y propaganda), libertad sindical, elección de representantes a la Asamblea Nacional francesa y a asambleas territoriales y consejos locales, aunque con poderes limitados y con doble colegio electoral, uno para los que disfrutaban de la ciudadanía francesa (los colonos y una minoría de evoloués) y otro para quienes, entre el resto, cumplían una serie de requisitos. La limitación de derechos políticos era el resultado de la Constitución de 1946, pues la no refrendada popularmente de 1945 era bastante más generosa con los nativos de las colonias. Se abolió también la odiada prestación personal. Y mientras que en las demás colonias los líderes nacionalistas apostaron por hacer de la Unión Francesa una verdadera estructura federal con Francia, reclamando el sufragio universal y la plena igualdad de derechos, en Camerún, territorio en fideicomiso de las Naciones Unidas, sus líderes políticos apostaron claramente por un horizonte de independencia plena. En ese país el Partido Comunista Francés impulsó, durante aquellos años, la formación de la Union des Syndicats Conféderés du Cameroun, que en septiembre de 1945 convocó una huelga general en Douala que derivó en sangrientos enfrentamientos. En abril de 1948, tres meses después de la protesta de Mikomeseng, su líder sindical, Um Nyobé, fundó la Union des populations camerounaises (UPC), partido vinculado también al PCF (THOBIE, 1990: 349-353, 366-370 y 390; MANNING, 1988: 139-143; MVEM, 1963: 421-426, 431, 436 y 481-482).

No obstante, si la efervescencia política del Camerún contrastaba con el inmovilismo y el aislamiento de la colonia guineana, el miedo de las autoridades españolas al contagio era limitado, y de ahí el carácter restringido de la represión. De hecho, el nacionalismo tardaría aún un decenio en organizarse. El papel del jefe Uganda en la más dura protesta de los jefes de Río Benito quedó sin castigo, quizás no sólo por su mayor lejanía del agitado Camerún, sino por su avanzada edad (más de cien años en muchos relatos ndowés y misioneros), su prestigio y 
sus cordiales relaciones con las autoridades españolas. ${ }^{82}$ Lo mismo que sus más radicales, pero individuales, iniciativas posteriores.

En el caso de Mikomeseng, como hemos visto, fueron las autoridades coloniales las primeras en relacionar la protesta con la amenaza de la agitación nacionalista, presente en el vecino Camerún. El suceso comenzó a correr de boca en boca, y una década después se convirtió en una tradición oral del nacionalismo guineocuatoriano.

\section{La tradición oral y las versiones escritas}

En 1959 se organizó por primera vez el movimiento nacionalista guineoecuatoriano bajo la dirección de Acacio Mañé y de Enrique Nvo Okenve, para rechazar la decisión unilateral del Gobierno franquista de convertir formalmente la colonia en dos nuevas provincias españolas. Se escribieron documentos de protesta que se hicieron llevar a la ONU a través de los Gobiernos de Camerún (aún no plenamente independiente) y de la Ghana de Nkrumah. Pero la idea inicial era presentar la protesta escrita ante el ministro de la Presidencia Carrero Blanco, cuya próxima visita se rumoreaba. ${ }^{83}$ Uno de los documentos encontrados en Camerún en la cartera de Enrique Nvo, cuando su supuesta y no aclarada desaparición por ahogamiento al cruzar un río a nado, es un borrador de discurso dirigido a la Asamblea General de Naciones Unidas, que decía que los nativos rechazaban la integración provincial, pero deseaban acordar «las relaciones que en lo sucesivo tendremos con España». "De buena gana hubiéramos acudido a la Presidencia del Gobierno Español [...], más temiendo la repetición del caso de 1947» habían preferido dirigirse directamente a la ONU pidiendo protección. «Para comunicar esta idea a la masa general, había que hacerlo de modo que se evite las represalias terroristas que tomarán las autoridades coloniales como verán tengo citado anteriormente al insinuar lo que ocurrió el año $1947 » .{ }^{84}$ En este

82 Si se suele afirmar que Uganda murió en 1960 con 115 años, IYANGA (1992), p. 154, rebaja esta edad a 106. Ver el radiograma de Bonelli a Uganda, 10-6-1947, en AGA, C 81/7534, exp. Carmelo Enguema.

83 AGA, C 81/9035, exp. Acacio Mañé: «Antecedentes» y encargado de despacho de la Secretaría General a subgobernador, 4-8-1959.

84 AGA, Africa, C 81/13041, Exp. Enrique Nvo: "Copiado de una libreta manuscrita", pp. 8-9.

ÉNDOXA: Series Filosóficas, n. 37, 2016, pp. 121-147. UNED, Madrid 
texto vemos la memoria del suceso de enero de 1948 con una fecha equivocada, que se repetirá normalmente, en la que se asocia aquella protesta a la plenamente nacionalista de 1959, y se resalta (y exagera) la represión de entonces (al mes siguiente a la desparición de Nvo, desapareció Acacio Mañé y según testimonios de primera mano había sido detenido por la policía de Bata, torturado y arrojado al mar) (MENÉNDEZ, 2008: 15-31).

Una carta de la dirección del Movimiento Nacional de Liberación de Guinea Ecuatorial (MONALIGE) a Franco, de 2 de mayo de 1966, afirmaba abiertamente: «Desde la llegada de los Ministros españoles a estos territorios en el año 1947 (...) el pueblo guineano siempre expresó su deseo de acogerse a la independencia por medio de documentos entregados a los augustos visitantes» (CAMPOS SERRANO, 2002: 68, n. 119). René Pelissier, en un artículo de 1966, recogía, sin duda de la tradición oral ndowé, que Uganda había pedido aquel año al ministro del Aire la descolonización por incumplimiento de los tratados firmados durante el reinado de Isabel II (PELISSIER, 1966: 77).

Finalmente, en su solemne discurso el día de la independencia, el 12 de octubre de 1968, el nuevo presidente Macías hizo un homenaje a quienes habían luchado por ella, lucha que remontó a 1939, cuando el país «empezó a organizarse en asociaciones reivindicativas y en 1947 nuestros jefes tradicionales entregaron a los ministros espańoles del Gobierno del Caudillo, sendos documentos de petición de independencia» (NSI, 2014: 67).

La memoria de la protesta de 1948 estaba viva entre los nacionalistas, que la habían convertido en una acción auroral de su propio movimiento. En 1983 Francisco Elá publicó un primer relato de la de Mikomeseng. Para Elá la protesta "sembró la semilla de nuestro nacionalismo», aunque éste tardara después un tiempo en organizarse. El resumen del escrito era: «Si es que somos españoles, que se nos trate como a tales; si no lo somos, que se nos deje en paz en nuestra tierra». Había sido redactado por Marcelo Asistencia y dos más, uno de ellos un camerunés miembro del movimiento de revitalización fang Alar Ayong, y se presentó a "los ministros», aunque concreta que eran Carrero Blanco y Díaz de Villegas. Los tres redactores, Carmelo Nguema y otro jefe más fueron deportados a Annobón, aunque los tres primeros huyeron a Camerún. Nguema estuvo diez años en la remota isla y sufrió confiscación de todos sus bienes y la venta de sus mujeres. Ante la sorpresa de la protesta, Carrero destituyó a Bonelli (ELÁ, 1983: 10-20). Otros autores fang han seguido luego en buena medida el relato de Elá, aunque con algunas variantes (NDONGO, 1998: 187-188; EKONG, 2010: 
69; OYONO, 2011: 65-66). Rosendo-Elá Nsué, que dice recibir el testimonio de un amigo de Carmelo Nguema, involucra en el incidente al posterior héroe nacionalista Enrique Nvo, aunque con un papel en el fondo poco airoso, pues éste había pedido a Nguema que ocultase su participación a cambio de sostener a su familia mientras estuviera preso. Nsué también alude a las actitudes nacionalistas del jefe Uganda (NSUÉ, 2007: 337-343). La protesta de Río Benito es recogida por la ndowé Cristina Dyombe (hija del jefe Dionisio Dyombre, firmante del escrito ${ }^{85}$, quien recoge con fidelidad los nombres de los protagonistas, que dice que se coordinaron con Marcelo Asistencia, aunque da sensación de que confunde la protesta de «1947» con la agitación nacionalista posterior a 1959 (DYOMBE, 2008: 41-45).

Finalmente, el P. Jesús Eyama recoge dos testimonios tardíos del suceso de Mikomeseng, uno de Fortunato Nzang Okenve, similar a los relatos de Elá y del recogido por Rosendo Nsué, y otro de Salvador Nzamio, en 2005, que es el que más se acerca a la documentación del archivo, y que también se hace eco del escrito presentado a los ministros por Uganda. El relato bastante fidedigno de Nzamio, aunque también involucra a Enrique Nvo, muestra cómo las modificaciones que la tradición oral hizo del suceso, resignificándolo en clave nacionalista, eludieron las memorias personales que no se acomodaban a esta intención. Nzamio afirma, por ejemplo, que se trataba de un «documento de adhesión al gobierno español» (EYAMA, sa: 58-59).

\section{Conclusión. Una mitificación nacionalista}

Los nacionalistas resignificaron la protesta de 1948 para mitificarla, en el sentido de convertirla en un suceso extraordinario, esclarecedor del enfrentamiento entre colonizadores y colonizados, una temprana manifestación de la protesta popular anticolonial. Y en este sentido los relatos que se transmitieron del suceso modificaron algunos aspectos del mismo. El principal, la vinculación de la protesta con el nacionalismo e incluso la demanda de independencia. Algo lejos de la realidad, aunque hay que señalar que la abundante retórica españolista de las protestas de 1942 quedaba muy disminuida en las de 1948. Sí pueden considerarse protonacionalistas las iniciativas de Uganda en los dos ańos siguientes, y es

85 Agradezco este dato a Marcelino Bondyale. 
cierta la actividad de Asistencia y Nguema en la primera agitación nacionalista posterior.

Si los primeros relatos orales hablaban de la protesta ante «los ministros», Elá introdujo la presencia de Carrero Blanco en el suceso, y así será recogido en casi todos los relatos posteriores. Carrero, subsecretario del la Presidencia en 1948, superior directo del director general de Marruecos y Colonias, debía ser un completo desconocido en la Guinea de la época. No así en los años sesenta, cuando ya tenía el rango de ministro (desde 1951), y más tras su visita a la colonia a finales de 1962, recibido en todas partes por "entusiastas» multitudes que, de modo parecido a la metrópoli en las giras territoriales del dictador, desfilaban ante él con pancartas con los lemas de "Viva Franco», «Viva España» o «Río Muni español». ${ }^{86}$ En 1967 pasaría a vicepresidente del Gobierno. Carrero era como la encarnación del poder de Franco en Guinea, la personificación de la maldad del poder colonial, ante la que alzaron su voz los jefes en 1948.

Otra de las «mitificaciones» nacionalistas se centra en el agrandamiento de la represión. Represión terrorista, largos años de confinamiento en Annobón, confiscación de bienes, "venta», incluso, de las mujeres, respecto a los dos represaliados. Cifra exigua que, en muchos relatos, se extiende a varios involucrados más, o directamente a "los jefes», jefes «tradicionales» que encarnan así al pueblo oprimido por la colonización que comienza a levantarse. También Cristina Dyombe subraya que todos los protagonistas del escrito de Río Benito fueron detenidos, obviando su posterior puesta en libertad sin ulteriores consecuencias.

Más confusa es la figura del gobernador Bonelli, destituido por Carrero a causa de la protesta, según varios de los relatos. Realmente Bonelli fue destituido un año después, y la causa fundamental fue su enfrentamiento con la Cámara Agrícola de Fernando Poo. Rosendo Nsué elogia su figura, modelo de colonizador benemérito, por contraste con los demás colonialistas explotadores (NSUÉ, 2007: 43). Aunque la protesta de Río Benito subrayaba que la prestación había empeorado notablemente con él. Su destitución en el relato no hace sino resaltar el (supuesto) enorme impacto que tuvo la protesta entre las autoridades españolas.

86 Ver en la Filmoteca Española el largo reportaje de NO-DO «Las provincias españolas de Africa. Vistas a través del viaje del Ministro Subsecretario de la Presidencia». 
En estos relatos las protestas de 1948 fueron el origen del nacionalismo guineoecuatoriano, en un momento en que por todas las colonias vecinas se estaban organizado partidos nacionalistas. Era una manera de ocultar el carácter tardío del nacionalismo organizado en la pequeña colonia española. Al margen de que sí estuvieran implantados, incluso desde mucho antes de la Guerra Civil, los movimientos de revitalización y resistencia pacífica a la colonización del Alar Ayong y del bwiti (éste entre los fang y los ndowés). Este último, especialmente, sí que mereció en los mismos años cuarenta una dura represión de las autoridades, con varios ajusticiamientos públicos de algunos de sus miembros, acusados de antropofagia. ${ }^{87}$ Un nacionalismo relativamente débil en la época de la clandestinidad, que sufrió detenciones y torturas, y la muerte de dos "mártires", Acacio Mañé y Enrique Nvó, nada comparable a los cientos de víctimas en la represión de los disturbios y agitaciones del nacionalismo congoleño, que permitió a Patrice Lumumba apelar al sufrimiento colectivo del pueblo en su lucha por la independencia, en su famoso discurso del día de su proclamación, en presencia del mismo rey belga Balduino (MONAVILLE, 2008: 89-93). En Guinea Ecuatorial no hubo ni aquel tipo de disturbios ni una represión equivalente. Por otra parte, los nacionalistas estuvieron siempre divididos en varios partidos, con frecuentes enfrentamientos personalistas, y muchos de ellos se pasaron al colaboracionismo cuando se aprobó el régimen autónomo en 1963. Lo que no quiere decir que el discurso anticolonial no hallara un enorme eco entre la población nativa cuando la propaganda nacionalista fue tolerada y la metrópoli encaminó al país hacia la independencia. El resentimiento por las humillaciones de la colonización era ampliamente compartido y fue fácil de movilizar pacíficamente. Los sucesos de 1948, aún mitificados, permitían un relato mucho más modesto que el del líder congoleño: el de una primera protesta nacionalista de los jefes, que actuaron como legítimos representantes de su pueblo.

87 AGA, C 81/8195, exp. 2. SÁNCHEZ MOLINA (1997), p. 243. 


\section{Bibliografía}

ARANZADI, J. (2009), «Supervivencias actuales del parentesco tradicional fang», en $I$ Jornadas de Antropologia de Guinea Ecuatorial, Madrid, UNED, pp. 63-123.

ARANZADI, J. (2016), Transformaciones de la sociedad bubi en el siglo XX, Madrid, UNED (próxima publicación).

BODLEY, J. (1996), Cultural Anthropology. Tribes, States and the Global System, Mountain View (California), Mayfeld (2a ed.).

CAMPOS SERRANO, A. (2002), De colonia a Estado: Guinea Ecuatorial, 1955-1968, Madrid, Centro de Estudios Políticos y Constitucionales.

DYOMBE DYANGANI, C. (2008), Identidad cultural Ndowe, Nueva York, Ndòwě International Press.

EKONG ANDEME, P. (2010), El proceso de descolonización de Guinea Ecuatorial, Madrid, Autor.

ELÁ, F. (1983), Guinea. Los últimos años, Santa Cruz de Tenerife, Centro de Cultura Popular Canaria.

EYAMA ACHAMA, J. R.-E. (s.a.), La Evangelización de Guinea Ecuatorial: Implantación de la Parroquia de "Nuestra Señora de África" de Mikomeseng (1927-1969), Tesis de licenciatura, Madrid, Universidad Pontificia de Comillas, Facultad de Teología.

HARRIS, M. (1971), Introducción a la antropología general, Madrid, Alianza.

IYANGA PENDI, Augusto (1998), El Pueblo Ndowé. Etnología, sociología e historia, Valencia, Nau Llibres.

LEWELLEN, T. (1983), Introducción a la Antropologia Politica, Barcelona, Bellaterra.

MANNING, P. (1988), Franco-phone subsaharan Africa 1880-1995, Cambridge, Cambridge University Press.

MENÉNDEZ HERNÁNDEZ, J. (2008), Los últimos de Guinea. El fracaso de la descolonización, Madrid, Sial.

MIRANDA JUNCO, A. (1945), Leyes coloniales, Madrid, Impr. Sucesores de Rivadeneyra.

MONAVILLE, P. (2008), "La crise congolaise de juillet 1960 et le sexe de la décolonisation", Sextant, no 24-25, pp. 87-102.

MVEM, E. (1963), Histoire du Cameroun, Paris, Prèsence africaine.

NDONGO, D. (1998), «Guineanos y españoles en la interacción colonial (19001968)», en M. DE CASTRO y D. NDONGO, España en Guinea. Construcción del desencuentro: 1778-1968, Madrid, Sequitur, págs. 107-217. 
NERÍN, G. (2015), Corisco y el estudario del Muni (1479-1931). Del aislamiento a la globalización y de la globalización a la marginación, París, L'Harmattan.

NSÍ OWONO-OKOMO, M. (2014), El proceso politico de Guinea ecuatorial, desde la independencia hasta la pre-democracia, Murcia, Universidad de Murcia.

NSUÉ MIBUY, R.-E. (2007), Historia de la Colonización y de la descolonización de Guinea Ecuatorial por España, Toledo, Impr. Grafillés.

OYONO AYINGONO, Sh. C. (2011), Acacio Mañé Elá una historia por contar, Malabo, Trifaldi.

PELISSIER, R. (1966), «Le mouvement nationaliste en Afrique espagnole», Le mois en Afrique, no 7, pp. 72-96.

RANCAÑO SERILLE, F. (1943), Observaciones referentes a los indigenas de la Guinea Continental Española, Febrero (manuscrito de la Biblioteca Nacional, signatura AFRC/7128/6).

SÁNCHEZ MOLINA, R. (1997), Las imágenes de los fang en los expedicionarios, misioneros y africanistas españoles durante la época colonial (1858-1959), Tesis de doctorado, UNED.

TESSMAN, G. (2008) [1923], Los bubis de Fernando Poo, Madrid, Sial.

THOBIE, J., G. MEYNIER, C. COQUERY-VIDROVITCH y Ch.-R. AGERON (1990), Histoire de la France coloniale 1914-1990, París, Armand Colin. 
